\title{
Patterns of Traumatic Injury Volume during First Year of COVID-19 Pandemic
}

\author{
Kristen D Nordham ${ }^{1}$, Scott Ninokawa ${ }^{2}$, Juan C Duchesne ${ }^{3}$
}

\begin{abstract}
Background: Here, we investigate the incidence of traumatic injuries during the COVID-19 pandemic over a year-long period which includes the first documented COVID-19 case in the US as well as rollout of vaccines. The study period includes the months of strictest lockdowns which early reports have focused on, as well as reopening.

Methods: This retrospective analysis was performed with all records of trauma patients from our level 1 trauma center's trauma registry. Mean weekly and total yearly patient counts from 2017-2019 and 2020 were compared using independent samples t-test or Mann-Whitney U test. Shapiro-Wilk and Levene's tests were used to assess normality and variances, respectively.

Results: There were more trauma patients in 2020 than the 2017-2019 average. In 2020, there were significantly higher weekly counts of penetrating injuries vs the 2017-2019 average [mean (SD)] [22.5 (7.2) vs 17.5 (3.1), $p<0.000$ ], specifically gunshot wounds (GSWs) [15.8 (6.0) vs $11.3(2.7), p<$ 0.0000 ] and more assaults [23.3 (6.7) vs $19.4(3.2), p<0.0003$ ]. In 2020, fewer falls [11.9 (4.3) vs $13.4(2.6), p<0.03]$, pedestrian/bicycle accidents [5.5 (3.1) vs 7.5 (2.1), $p<0.0002$ ], and accidents in general [45.9 (17.1) vs $50.9(5.6), p<0.05]$ presented to our hospital compared to previous years. Overall, weekly totals were higher than average in 2020, but were lower than average during the strictest shutdowns from March 18 to May 15. Conclusion: During the first 3 months and strictest lockdown of the pandemic, the number of traumatic injuries was significantly lower than average. Once restaurants reopened at $50 \%$ capacity, bars reopened, and gatherings of $<50$ people were allowed, weekly counts of trauma patients were above average in most $(26 / 32,81 \%)$ weeks through the end of the year. Increased GSWs and assaults this year may suggest increased interpersonal conflict. Increased violent and traumatic injury necessitating medical care is concerning for emergency departments and hospitals already overloaded with patient volume and facing staffing shortages due to the COVID-19 pandemic.
\end{abstract}

Keywords: Accident, Emergency, Gunshot injury, Pandemics, Surgery, Trauma.

\section{INTRODUCCIÓN}

Objetivo: Aquí, investigamos la incidencia de lesiones traumáticas durante la pandemia de COVID-19 durante un período de un año que incluye el primer caso documentado de COVID-19 en los Estados Unidos. Así como el lanzamiento de vacunas. El período de estudio incluye los meses de cierres más estrictos en los que se han centrado los primeros informes, así como la reapertura.

Materiales y métodos: Este análisis retrospectivo se realizó con todos los registros de pacientes con trauma del registro de trauma de nuestro centro de trauma de nivel 1. Los recuentos medios semanales y totales anuales de pacientes de 2017-2019 y 2020 se compararon. mediante la prueba t de muestras independientes o la prueba U de Mann-Whitney. Se utilizaron las pruebas de Shapiro-Wilk y Levene para evaluar la normalidad y las variaciones, respectivamente.

Resultados: Hubo más pacientes con trauma en 2020 que el promedio de 2017-2019. En 2020, hubo recuentos semanales significativamente más altos de lesiones penetrantes en comparación con el promedio de 2017-2019 (media [DE]) $(22,5$ [7, 2] vs 17, 5 [3, 1], $p<0.000)$, específicamente heridas de bala (GSW) $(15,8[6,0]$ vs $11,3[2,7], p<0.0000)$ y más agresiones $(23,3[6,7]$ vs $19,4[3,2], p<0.0003)$. En 2020, menos caídas $(11,9[4$, $3]$ vs $13,4[2,6], p<0.03)$, accidentes de peatones/bicicletas $(5,5[3,1]$ vs $7,5[2,1], p<0.0002)$ y accidentes en general $(45,9[17,1]$ vs $50,9[5,6], p$ $<0.05)$ presentados en nuestro hospital en comparación con años anteriores. En general, los totales semanales fueron más altos que el promedio en 2020, pero fueron más bajos que el promedio durante los cierres más estrictos del 18 de marzo al 15 de mayo.

Conclusión: Durante los primeros tres meses y el confinamiento más estricto de la pandemia, el número de lesiones traumáticas fue significativamente más bajo que el promedio. Cuando los restaurantes volvieron a abrir al $50 \%$ de su capacidad, los bares volvieron a abrir y se permitieron reuniones de menos de 50 personas, el conteo semanal de pacientes con trauma estuvo por encima del promedio en la mayoría de las semanas $(26 / 32,81 \%)$ hasta el final del año. El aumento de GSW y agresiones este año puede sugerir un aumento de los conflictos interpersonales. El aumento de las lesiones violentas y traumáticas que requieren atención médica es preocupante para los departamentos de emergencia y los hospitales que ya están sobrecargados con el volumen de pacientes y enfrentan escasez de personal debido a la pandemia de COVID-19.

Palabras clave: Accidente, Cirugía, Emergencia, Herida de bala, Pandemias, Trauma.

Panamerican Journal of Trauma, Critical Care \& Emergency Surgery (2021): 10.5005/jp-journals-10030-1351

\footnotetext{
1-3Department of Trauma \& Acute Care Surgery, Tulane University School of Medicine, New Orleans, Louisiana, United States

Corresponding Author: Kristen D Nordham, Department of Trauma \& Acute Care Surgery, Tulane University School of Medicine, New Orleans, Louisiana, United States, Phone: +1 504-988-2317, e-mail: knordham@tulane.edu

How to cite this article: Nordham KD, Ninokawa S, Duchesne JC. Patterns of Traumatic Injury Volume during First Year of COVID-19 Pandemic. Panam J Trauma Crit Care Emerg Surg 2021;10(3):95-100.

Source of support: Nil

Conflict of interest: None
}

(O)TheAuthor(s). 2021 Open Access This article is distributed under the terms of the Creative Commons Attribution 4.0 International License (https://creativecommons. org/licenses/by-nc/4.0/), which permits unrestricted use, distribution, and non-commercial reproduction in any medium, provided you give appropriate credit to the original author(s) and the source, provide a link to the Creative Commons license, and indicate if changes were made. The Creative Commons Public Domain Dedication waiver (http://creativecommons.org/publicdomain/zero/1.0/) applies to the data made available in this article, unless otherwise stated. 


\section{INTRODUCTION}

The first case of COVID-19 was confirmed in the United States on 20th January 2020, and the first case in the state of Louisiana was reported on 9th March 2020., ${ }^{1,2}$ By the end of 2020, there were over 20 million confirmed cases and nearly 350,000 deaths in the US alone. ${ }^{3}$ Efforts to reduce spread of COVID-19 have included social distancing, closure of nonessential businesses and schools, and a shift towards remote working for office-based jobs. These social distancing recommendations and lockdowns may have had other unintended effects on community health beyond blunting the spread of COVID-19, as indicated by numerous articles investigating the incidence of traumatic injury during the pandemic.

Reports on the subject of COVID-19's impact on the incidence of traumatic injury have shown a decrease in the number of trauma patient volume after closure of nonessential business and activities and social distancing mandates. ${ }^{4-7}$ A study focusing on maxillofacial trauma found that there were fewer patients presenting, but the severity of those cases was higher than cases of past years. ${ }^{8}$ Another study found an increase from the previous year in number of injuries due to assault, self-harm jumping, and falling/jumping/being pushed. ${ }^{9}$ Even with decreased numbers of total trauma patients in early 2020 due to lockdowns, trauma centers have ultimately reported increased numbers of intentional violent injury, especially stabbing and gunshot wounds (GSW). ${ }^{10,11}$ These injury patterns are worrisome for violence, assault, abuse, and self-harm, all of which have community-level impacts beyond the individual injuries. Likewise, the pandemic's social distancing and stayhome orders have raised concern for increased elder abuse, child mistreatment, and domestic violence. ${ }^{12-14}$ Reporting of such events has been complicated by decreased interaction with individuals outside the household who may normally be the ones to file reports, such as mandated reporters.

Published reports regarding trauma volume during the COVID-19 pandemic focus on data from the first few months of the pandemic or first half of the year, which coincided with the strictest lockdowns and restrictions. Here, we aim to examine the impact of the COVID-19 pandemic and various government responses on the incidence of traumatic for the whole of 2020 to better understand the longer-term effects of the pandemic.

\section{Methods}

\section{Setting and Design}

This is a retrospective analysis of trauma patients admitted to our level 1 trauma center, from January 2017 through December 2020. This study was determined to be not human subjects research by our university and hospital Institutional Review Board. Patients were identified by the institutional trauma registry. All patients who met trauma patient criteria were included in our counts: trauma activations, trauma transfers, and admitted trauma patients. We compared mean weekly, monthly, and total yearly counts of trauma patients presenting to our hospital from 2017-2020.

March 18, 2020, is the date that divides our study timeframe between prelockdown and lockdown, as this is when local governmental stay-home orders were put in place. In this study, we will define 1st January to 17th March as prelockdown, 18th March to 15th May as lockdown, and 16th May to 31st December as reopening. We also investigate the timing of governmental policies including stay-home orders, restrictions on businesses, and reopening in correlation with trauma patient counts in our hospital at those times.

\section{Statistical Analysis}

The numbers of trauma patients before and after social distancing measures were put into place were compared using the independent samples $t$-test or Mann-Whitney $U$ test. Shapiro-Wilk and Levene's tests were used to assess normality and variances, respectively. Nonparametric distributions are presented as median [IQR], normal distributions are presented as mean (standard deviation), unless otherwise noted. Differences were considered significant when a two-sided $p$-value $<0.05$.

\section{Results}

\section{Demographics}

Of 4,157 trauma patients treated at our hospital in 2020, $73 \%$ were male, consistent with all yearly totals and averages since 2017 (Table 1). The number of trauma patients in age-groups $(<18$, 18-34, 35-64, and $>65$ ) were similar between years, as was type of transport to the hospital. Of the 4,157 trauma patients in 2020, 2,774 (67\%) presented with blunt injuries, 1,197 (24\%) penetrating, 169 (4\%) thermal, $6(0.1 \%)$ drowning, and 11 (0.2\%) unspecified injury type (Table 2).

\section{Mechanism and Total Counts of Trauma Patients}

In 2020, there were significantly more total injuries per week [mean (SD)] [79 (3.5) vs 73 (6.1), $p=0.03$ ] as well as injuries caused by penetrating mechanisms [22.5 (7.2) vs 17.5 (3.1), $p<0.000]$, and GSWs [15.8 (6.0) vs $11.3(2.7), p<0.0000]$ and fewer weekly falls [11.9 (4.3) vs $13.4(2.5), p<0.03]$ and pedestrian or bicycle accidents [5.5 (3.1) vs 7.5 (2.1), $p<0.0002$ ] than 2017-2019 averages (Table 3). There were significantly more weekly trauma injuries due to assaults [23.3 (6.7) vs 19.4 (3.2), $p<0.0003$ ] and fewer injuries due to accidents [45.9 (17.1) vs 50.9 (5.6), $p<0.05$ ] in 2020 compared to prior years.

In 2020, there were significantly more tier I activations compared to previous years [30.3 (7.9) vs $25.9(3.8), p<0.0005]$ and more tier II activations [32.5 (8.9) vs 29.8 (4.7), $p<0.05$ ], while the number of weekly trauma consults were not significantly different. Before 18th March2020, there was no significant difference in number of weekly trauma patients compared to the 2017-2019 average ([78 (15.7) vs 70 (9.0), $p=0.16$ ] (Fig. 1). There was a significant decrease in number of weekly trauma patients during lockdown, beginning on 18th March, when first stay-home orders were put into place compared to the same time period in previous years [65 (17.1) vs 78 (7.3), $p<0.02]$. Once restrictions were lifted on 15th May 2020, there was a higher average number of weekly traumas through the end of the year compared to the same time periods of previous years [84 (13.1) vs 72 (11.6), $p<0.0001$ ] (Fig. 1).

Looking at the lockdown periods with regard to only GSWs, there was no difference between number of weekly GSWs in 2020 and previous years before lockdown [10 (2.9) vs 12 (2.9), $p=0.26$, or during lockdown [12 (4.6) vs 14 (4.4), $p=0.42$ ]. However, after reopening began, there were significantly more GSWs per week compared to previous years [19 (5.0) vs 12 (3.3), $p<0.0001]$ (Fig. 2).

\section{Discussion}

\section{Prelockdown}

During the early months of 2020, prior to enforcement of social distancing mandates in the state of Louisiana on 18th March 2020, 
Table 1: Demographics presented as $(n)$

\begin{tabular}{|c|c|c|c|c|c|}
\hline & 2017 & 2018 & 2019 & 2017-2019 Average & 2020 \\
\hline \multicolumn{6}{|l|}{ Sex } \\
\hline Male & 2,637 & 2,722 & 2,989 & 2,786 & 3,055 \\
\hline Female & 927 & 1,112 & 1,221 & 1,083 & 1,122 \\
\hline \multicolumn{6}{|c|}{ Age in years by age-group } \\
\hline$<18$ & 356 & 345 & 463 & 387 & 457 \\
\hline $18-34$ & 1,426 & 1,380 & 1,474 & 1,393 & 1,497 \\
\hline $35-65$ & 1,497 & 1,725 & 1,852 & 1,702 & 1,788 \\
\hline$>65$ & 285 & 383 & 421 & 387 & 416 \\
\hline Average age & 39 & 40 & 40 & 40 & 39 \\
\hline \multicolumn{6}{|l|}{ Race } \\
\hline Asian & 34 & 42 & 54 & 43 & 40 \\
\hline Black & 1,792 & 1,919 & 2,146 & 1,950 & 2,324 \\
\hline Hispanic & 201 & 211 & 263 & 225 & 259 \\
\hline White & 1,409 & 1,538 & 1,628 & 1,509 & 1,450 \\
\hline Pacific Islander & 3 & 0 & 5 & 3 & 3 \\
\hline Other & 121 & 123 & 108 & 142 & 337 \\
\hline Native American & 4 & 1 & 6 & 4 & 3 \\
\hline \multicolumn{6}{|l|}{ Transport } \\
\hline Ground ambulance & 2,844 & 3,055 & 3,362 & 3,057 & 3,376 \\
\hline Air ambulance & 242 & 267 & 267 & 619 & 321 \\
\hline Police & 0 & 1 & 0 & 0 & 2 \\
\hline Other & 478 & 511 & 581 & 255 & 458 \\
\hline Transfer & 479 & 642 & 790 & 557 & 665 \\
\hline
\end{tabular}

Table 2: Injury characteristics presented as $(n)$

\begin{tabular}{|c|c|c|c|c|c|}
\hline & 2017 & 2018 & 2019 & 2017-2019 Average & 2020 \\
\hline \multicolumn{6}{|l|}{ Sex } \\
\hline Male & 2,637 & 2,722 & 2,989 & 2,786 & 3,055 \\
\hline Female & 927 & 1,112 & 1,221 & 1,083 & 1,122 \\
\hline \multicolumn{6}{|c|}{ Age in years by age group } \\
\hline$<18$ & 356 & 345 & 463 & 38 & 457 \\
\hline $18-34$ & 1,426 & 1,380 & 1,474 & 1,393 & 1,497 \\
\hline $35-65$ & 1,497 & 1,725 & 1,852 & 1,702 & 1,788 \\
\hline$>65$ & 285 & 383 & 421 & 387 & 416 \\
\hline Average age & 39 & 40 & 40 & 40 & 39 \\
\hline \multicolumn{6}{|l|}{ Race } \\
\hline Asian & 34 & 42 & 54 & 43 & 40 \\
\hline Black & 1,792 & 1,919 & 2,146 & 1,950 & 2,324 \\
\hline Hispanic & 201 & 211 & 263 & 225 & 259 \\
\hline White & 1,409 & 1,538 & 1,628 & 1,509 & 1,450 \\
\hline Pacific Islander & 3 & 0 & 5 & 3 & 3 \\
\hline Other & 121 & 123 & 108 & 142 & 337 \\
\hline Native American & 4 & 1 & 6 & 4 & 3 \\
\hline \multicolumn{6}{|l|}{ Transport } \\
\hline Ground ambulance & 2,844 & 3,055 & 3,362 & 3,057 & 3,376 \\
\hline Air ambulance & 242 & 267 & 267 & 619 & 321 \\
\hline Police & 0 & 1 & 0 & 0 & 2 \\
\hline Other & 478 & 511 & 581 & 255 & 458 \\
\hline Transfer & 479 & 642 & 790 & 557 & 665 \\
\hline
\end{tabular}


Table 3: Weekly mean (standard deviation) number of trauma injuries by injury type, mechanism, and intent comparing 2017-2019 averages to 2020 counts

\begin{tabular}{|c|c|c|c|c|c|}
\hline & 2017 & 2018 & 2019 & 2017-2019 Average & 2020 \\
\hline Total injuries & 3,564 & 3,834 & 4,210 & 3,869 & 4,157 \\
\hline Average monthly & 292 & 314 & 344 & 316 & 346 \\
\hline Average weekly & 67 & 72 & 79 & 73 & 79 \\
\hline \multicolumn{6}{|l|}{ Injury type } \\
\hline Blunt & 2,593 & 2,805 & 2,955 & 2,784 & 2,774 \\
\hline Penetrating & 952 & 829 & 977 & 919 & 1,197 \\
\hline Thermal & 13 & 185 & 266 & 155 & 169 \\
\hline Drowning & 2 & 6 & 7 & 5 & 6 \\
\hline Unspecified & 4 & 9 & 5 & 6 & 11 \\
\hline \multicolumn{6}{|l|}{ Mechanism } \\
\hline Fall & 670 & 729 & 754 & 718 & 626 \\
\hline MVC & 1,058 & 1,244 & 1,352 & 1,218 & 1,181 \\
\hline Pedestrian or bike accident & 395 & 399 & 398 & 397 & 288 \\
\hline GSW & 646 & 513 & 612 & 590 & 840 \\
\hline Stab & 274 & 253 & 293 & 273 & 308 \\
\hline Crush & 8 & 14 & 22 & 15 & 18 \\
\hline Burn & 13 & 119 & 203 & 112 & 106 \\
\hline Explosion & 9 & 23 & 11 & 14 & 11 \\
\hline Drowning & 2 & 6 & 7 & 5 & 6 \\
\hline Brawl & 163 & 144 & 166 & 158 & 133 \\
\hline Toxic exposure & & 6 & 14 & 10 & 5 \\
\hline Other & 326 & 384 & 378 & 363 & 635 \\
\hline \multicolumn{6}{|l|}{ Intent } \\
\hline Legal intervention & 11 & 14 & 12 & 12 & 15 \\
\hline Assault & 1,087 & 944 & 1,043 & 1,025 & 1,241 \\
\hline Accident & 2,337 & 2,769 & 3,037 & 2,714 & 2,426 \\
\hline Self-inflicted & 92 & 66 & 72 & 77 & 87 \\
\hline Unspecified & 37 & 41 & 46 & 41 & 388 \\
\hline \multicolumn{6}{|l|}{ Activation tier } \\
\hline Tier I & 1,414 & 1,319 & 1,327 & 1,353 & 1,600 \\
\hline Tier II & 1,389 & 1,518 & 1,754 & 1,554 & 1,712 \\
\hline Trauma consults & 761 & 997 & 1129 & 962 & 845 \\
\hline
\end{tabular}

GSW, gunshot wound; MVC, Motor Vehicle Collision

the number of weekly trauma patients was not significantly different compared to previous years. Likewise, there was no difference between the number of GSW during these months compared to the same months of previous year.

\section{Lockdown}

The state of emergency declared on 18th March 2020 closed all nonessential businesses such as bars, casinos, theaters, and dine-in restaurants. Essential facilities were allowed to stay open with minimal capacity (25\%) limits or outdoor operations. Most notably, bars were closed during the 3-month period of March to May. This phase was termed "lockdown," with no definitive end date provided, however, it eventually ended on 15th May 2020, with progression into the first stages of reopening.

During this initial period of strictest lockdown, we observed a significant decrease in the total number of traumatic injuries compared to previous years in the months of March, April, and May of 2020. Early during this phase, many hospitals also saw a decrease in stroke and heart attack activations, prompting worry that potential patients who would have gone to a hospital for concerning symptoms, forwent treatment. ${ }^{15,16}$ Similarly, especially during the early weeks of the pandemic, when social fears were at a high, patients with traumatic injuries may have been reluctant to seek care at a large hospital due to concerns of exposure to COVID-19 at a hospital. For this reason, it may be difficult to truly collect an accurate census regarding patient injuries, however, we would hope that patients with injuries severe enough to be included in this study would sought some form of healthcare.

\section{Reopening}

State-wide stay-at-home orders were in effect through 15th May, until "Phase One" opening of businesses allowed 25\% capacity at select businesses including childcare, food services establishments, houses of worship, and gyms. On 5th June restaurants were allowed to open to $50 \%$ capacity, indoor gatherings of up to 50 people were allowed, and bars opened. 


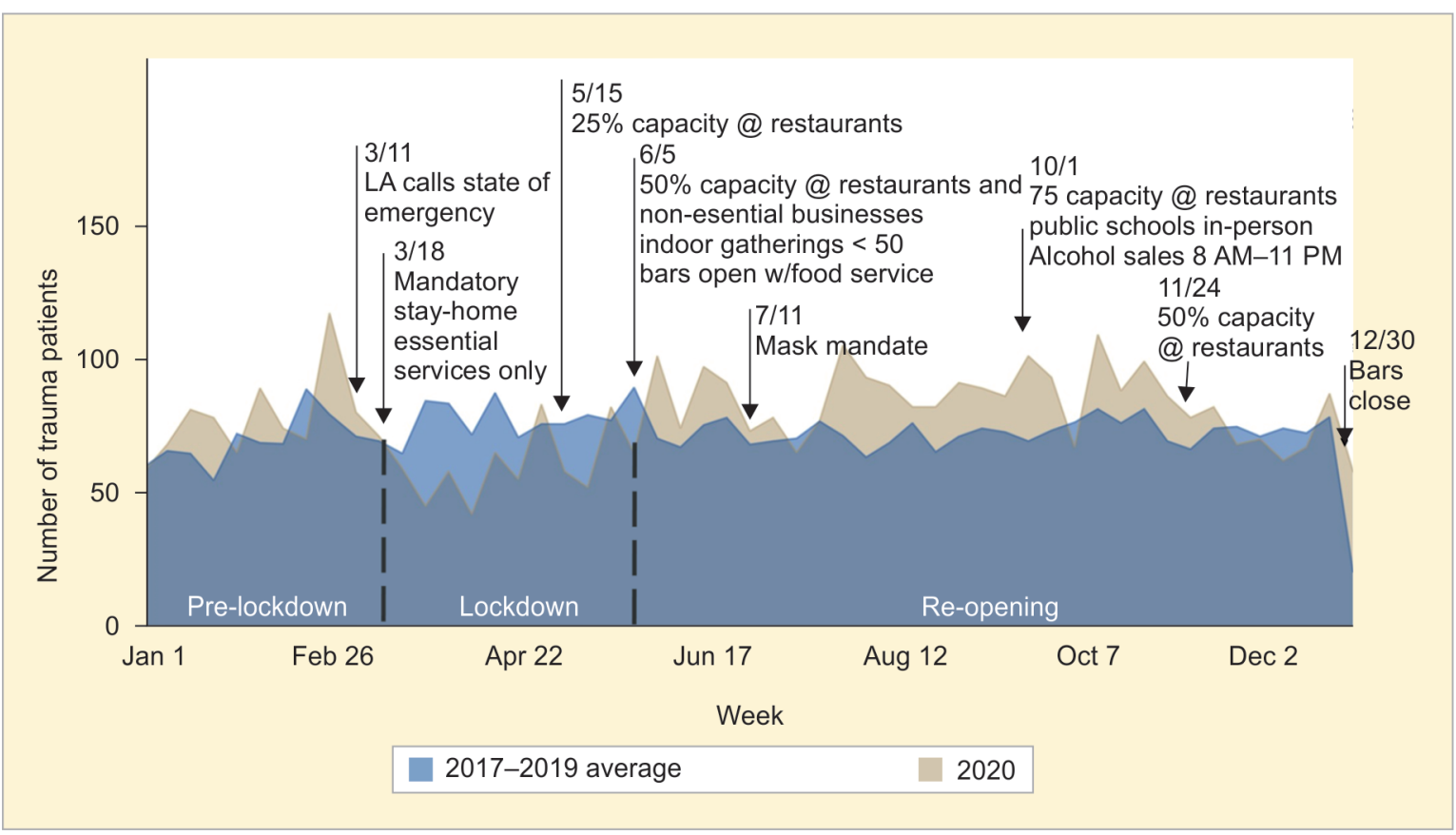

Fig. 1: Weekly trauma patient count-2020 compared to 2017-2019 average

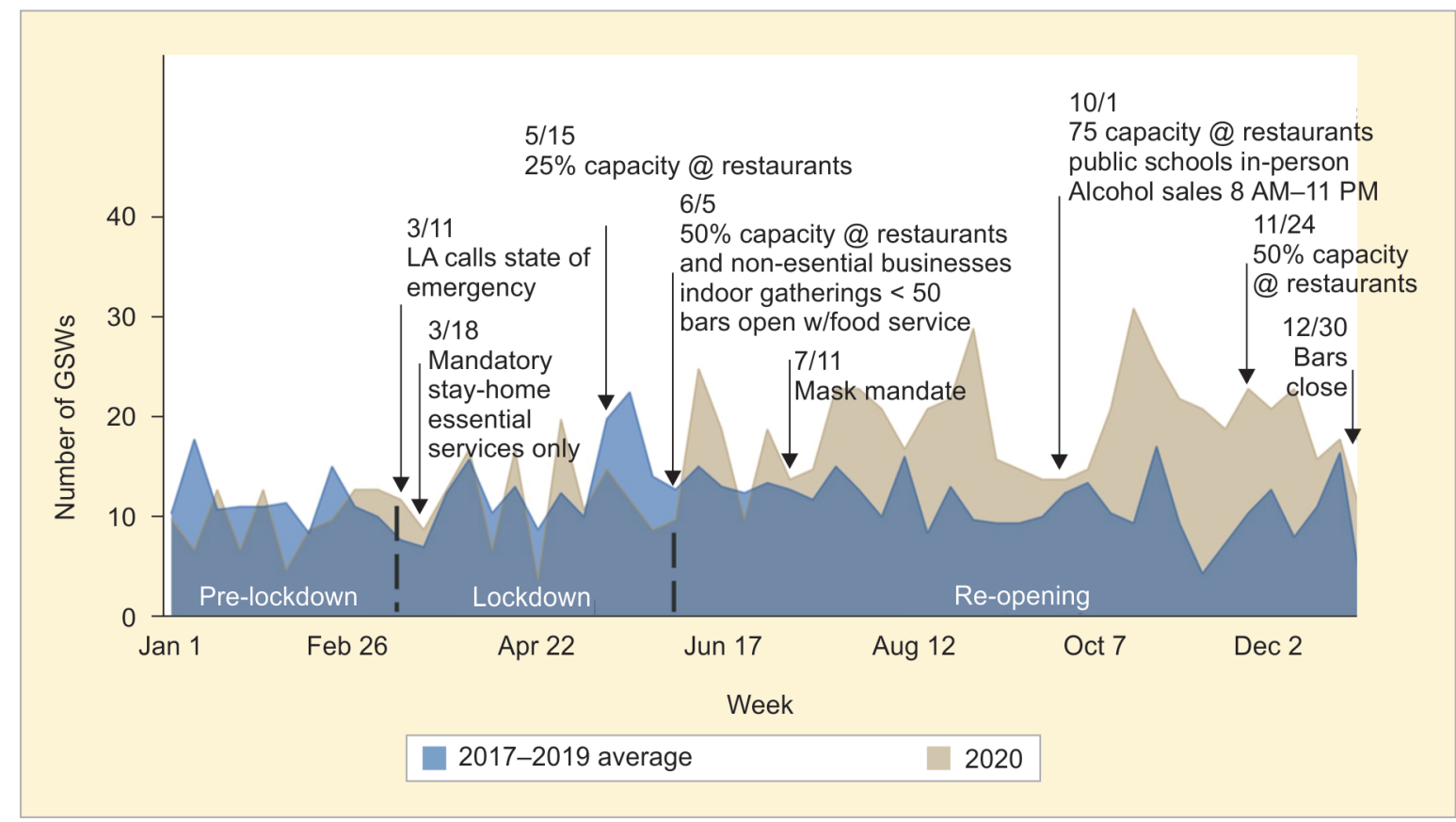

Fig. 2: Weekly gunshot wound count-2020 compared to 2017-2019 average

In June, the monthly and weekly counts of trauma patients rose to higher than average numbers. Once this reopening began, there were significantly more total injuries and GSWs compared to previous years.

From June onwards, the average weekly and monthly numbers of trauma patients treated was above average. Overall, despite the decrease in number of patients during the first 3 months of lockdown, more trauma patients were treated at our hospital in 2020 than the average of the three preceding years.

On 1st October restaurants and other businesses were allowed to run at $75 \%$ capacity, liquor sales were allowed from 8 am until
$11 \mathrm{pm}$, public schools resumed in-person learning. Despite these additional reopenings, there was a constant threat that lockdowns could revert back to tighter restrictions if the number of new COVID-19 cases increased significant or placed too high of a burden on local hospitals.

There were significantly more tier I and tier II activations during 2020, but no difference in trauma consults. While we did not have access to formal injury severity scores, tier l and II activation status can be used as a proxy for severity. Thus, it appears that in 2020, there was an increase in the number of critically injured patients compared to previous years. Our area did not experience a rearrangement in the 
regional trauma system due to overwhelming capacity issues, so it is unlikely that differences in traumatic injury volume at our hospital were due to decreased access to other hospitals. Additionally, the volume of patients transferred to our trauma center from outside hospitals was comparable to previous years.

As more injuries were due to assault (including penetrating wounds, specifically GSWs) and fewer to accidents (like falls and pedestrian/bicycle accidents), multiple conclusions can be made regarding injury patterns. Assaults may have increased in rate due to increased interpersonal conflict fueled by more time spent at home, stress caused by the COVID-19 pandemic and other world events, increased unemployment rates, or other interpersonal stressors. Accidents may have presented in decreased rates to our hospital due to an actual decreased number of accidents. Conversely, those who experienced accidents such as falls may have justified not seeking medical care at a hospital treating COVID-19 patients by the lack of obvious signs of severe like hemorrhage after a penetrating wound, which perhaps more obviously require medical care.

The number of firearms sold legally in the US doubled between March and August $2020(n=12,233,3000)$ compared to those months in 2019 ( $n=6,38,6000) .{ }^{17}$ While this may have contributed to an increase in gun-related violence, there was also concern about the effects this would have on self-inflicted injuries, given that approximately $66 \%$ of firearm-related deaths are due to self-injury or suicide. While our data did not show an increase in self-inflicted wounds, future studies should be performed using national data or coroner records to determine accurate suicide rates, as many patients may have died on-scene and thus were transported directly to a coroner rather than a hospital.

\section{Limitations}

There are limitations to our study, which only includes data from a single level I trauma center, and thus injury characteristics may vary compared to other areas and national trends. Our trauma database only includes patients transported to our hospital, and thus does not include deaths outside of the hospital transported directly to the coroner including suicides, fatal traumatic injuries on-scene, and deaths of traumatically injured patients who did not seek medical attention. Additionally, our database had access to tier level of trauma activation, and while this does correlate to injury severity, our data had a large number of database entries with no tier level information, thus use of injury severity scores will be useful in similar future studies.

\section{Conclusion}

A 3-month decrease in number of traumatic injuries was observed after initial states of emergency were called due to the COVID-19 pandemic. This correlated with the strictest stay home mandates and public adherence with social distancing policies. Once restrictions eased, rates of traumatic injuries increased to rates higher than the previous 3 years. Overall, during the first year of the COVID-19 pandemic, our hospital treated more assaults including penetrating wounds, namely GSWs, and fewer accidents including falls and bicycle and pedestrian accidents. This information is important for policy-making, preparation, and managing of future events similar to the COVID-19 pandemic that may cause similar stressors such as natural disasters and manmade catastrophes. The present information may prove useful for preparedness for and prevention of violent injury during future periods of social isolation and stress by medical and public health partners. More immediately, current news reports from individual hospitals across the country are concerning for nursing and staffing shortages in in-patient and emergency department settings. With staffing shortages decreasing the capacity of hospitals and emergency departments and already long wait times for patients seeking care in emergency departments, an increase in the number of traumatic injuries is concerning for further overwhelming our hospital systems which are already stretched thin.

\section{References}

1. Harcourt J, Tamin A, Lu X, et al. Severe acute respiratory syndrome coronavirus 2 from patient with coronavirus disease, United States. Emerg Infect Dis 2020;26(6):1266-1273. DOI: 10.3201/eid2606.200516

2. Gov. Edwards Confirms Louisiana's First Presumptive Positive Case of COVID-19. In: Health LDo, ed.https://ldh.la.gov/: Louisiana Department of Health; 2020.

3. Cumulative Cases by Date. In: Medicine JHU, ed.https://coronavirus. jhu.edu/data/cumulative-cases2021.

4. Ninokawa S, Nordham KD, Tatum D, et al. Effects of social distancing on the incidence of traumatic injuries. Panamerican J Trauma 2020;9(2):4. DOI: 10.5005/jp-journals-10030-1277

5. Kamine TH, Rembisz A, Barron RJ, et al. Decrease in trauma admissions with COVID-19 pandemic. West J Emerg Med 2020;21(4):819-822. DOI: 10.5811/westjem.2020.5.47780

6. Forrester JD, Liou R, Knowlton LM, et al. Impact of shelter-in-place order for COVID-19 on trauma activations: Santa Clara County, California, March 2020. Trauma Surg Acute Care Open 2020;5(1):e000505. DOI: 10.1136/tsaco-2020-000505

7. Lara-Reyna J, Yaeger KA, Rossitto CP, et al. "Staying Home"-early changes in patterns of neurotrauma in New York City during the COVID-19 pandemic. World Neurosurg 2020;143:e344-e350. DOI: 10.1016/j.wneu.2020.07.155

8. Ludwig DC, Nelson JL, Burke AB, et al. What is the effect of COVID19-related social distancing on oral and maxillofacial trauma? J Oral Maxillofac Surg 2021;79(5):1091-1097. DOI: 10.1016/j.joms.2020.12.006

9. Rhodes HX, Petersen K, Biswas S. Trauma trends during the initial peak of the COVID-19 pandemic in the midst of lockdown: experiences from a rural trauma center. Cureus 2020;12(8):e9811. DOI: 10.7759/cureus.9811

10. Abdallah $\mathrm{HO}$, Zhao C, Kaufman E, et al. Increased firearm injury during the COVID-19 pandemic: a hidden urban burden. J Am Coll Surg 2021;232(2):159-168. DOI: 10.1016/j.jamcollsurg.2020.09.028

11. Chodos M, Sarani B, Sparks A, et al. Impact of COVID-19 pandemic on injury prevalence and pattern in the Washington, DC Metropolitan Region: a multicenter study by the American College of Surgeons Committee on Trauma, Washington, DC. Trauma Surg Acute Care Open 2021;6(1):e000659. DOI: 10.1136/tsaco-2020-000659

12. Makaroun LK, Beach $S$, Rosen $T$, et al. Changes in elder abuse risk factors reported by caregivers of older adults during the COVID-19 pandemic. J Am Geriatr Soc 2020. DOI:10.1111/jgs.17009

13. Lawson M, Piel MH, Simon M. Child maltreatment during the COVID19 pandemic: consequences of parental job loss on psychological and physical abuse towards children. Child Abuse Negl 2020;110(Pt 2):104709. DOI:10.1016/j.chiabu.2020.104709

14. Boserup B, McKenney M, Elkbuli A. Alarming trends in US domestic violence during the COVID-19 pandemic. Am J Emerg Med 2020;38(12):2753-2755. DOI: 10.1016/j.ajem.2020.04.077

15. Teo KC, Leung WCY, Wong YK, et al. Delays in stroke onset to hospital arrival time during COVID-19. Stroke 2020;51(7):2228-2231. DOI: 10.1161/STROKEAHA.120.030105

16. Decline in Stroke and Heart Attack Activations Across Louisiana Creates Concern [press release]. Louisiana Emergency Response Network, April 21, 20202020.

17. Statista Research Department. Monthly unit sales of firearms in the United States from 2019 to 2020 , by type.https://www.statista.com/ statistics/1107651/monthly-unit-sales-of-firearms-by-type-us/. 